\title{
Interação com ambientes e estabilidade de genótipos de feijoeiro-comum na Região Centro-Sul do Brasil
}

\author{
Leonardo Cunha Melo(1), Patrícia Guimarães Santos Melo(2), Luis Cláudio de Faria(1), José Luiz Cabrera Diaz ${ }^{(1)}$, \\ Maria José Del Peloso(1), Carlos Augustin Rava(1) e Joaquim Geraldo Cáprio da Costa ${ }^{(1)}$
}

\begin{abstract}
(1)Embrapa Arroz e Feijão, Rod. Goiânia/Nova Veneza, Km 12, CEP 75375-000 Sto Antônio de Goiás, GO. E-mail: leonardo@cnpaf.embrapa.br, Icfaria@cnpaf.embrapa.br, cabrera@cnpaf.embrapa.br, mjpeloso@cnpaf.embrapa.br, rava@cnpaf.embrapa.br, caprio@cnpaf.embrapa.br (2)Universidade Federal de Goiás, Escola de Agronomia e Engenharia de Alimentos, Setor de Melhoramento de Plantas, Rod. Goiânia/ Nova Veneza Km 0, CEP 74001-970 Goiânia, GO. E-mail: pgsantos@agro.ufg.br
\end{abstract}

\begin{abstract}
Resumo - O objetivo deste trabalho foi avaliar a estabilidade e adaptabilidade de genótipos, do programa de melhoramento genético do feijoeiro-comum, da Embrapa Arroz e Feijão, e comparar os métodos de AMMI (análise da interação multiplicativa e dos efeitos principais aditivos), de Lin \& Binns e de Eberhart \& Russell. Os ensaios foram compostos de 20 genótipos (grupos comerciais de grão preto, carioca, roxo, jalo e rajado), avaliados em 22 ensaios, na época das águas (safra) e na seca (safrinha) dos anos de 2002, 2003 e 2004, nos estados do Paraná, Santa Catarina e São Paulo. Foi encontrada baixa associação entre os métodos AMMI e Lin \& Binns $(\mathrm{r}=0,39)$, e AMMI e Eberhart \& Russell $(\mathrm{r}=0,40)$. Não houve correlação entre Lin \& Binns e Eberhart \& Russell. Os genótipos mais estáveis e produtivos, para tipo de grão comercial carioca são: as cultivares BRS Requinte e a linhagem CNFC 8075; para tipo de grão comercial preto, as cultivares BRS Supremo e BRS Campeiro; e para tipos de grãos comerciais roxo e rosinha, a cultivar BRS Vereda.
\end{abstract}

Termos para indexação: Phaseolus vulgaris, adaptabilidade, produtividade de grãos.

\section{Interaction with environment and stability of common bean genotypes in the South Centre Region of Brazil}

\begin{abstract}
The objective of this work was to evaluate the stability and adaptability of genotypes of the common bean breeding program of Embrapa Arroz e Feijão, and to compare the methods AMMI, Lin \& Binns and Eberhart \& Russell. Twenty breeding lines and cultivars, belonging to the following commercial group of grain: black, carioca, pink, jalo, and pinto, were evaluated in 22 variety trials, during the rainy and dry seasons of 2002, 2003 and 2004, in the states of Santa Catarina, Paraná and São Paulo. There was low association between the methods AMMI and Lin\& Binns $(r=0.39)$ and AMMI and Eberhart \& Russell $(r=0.40)$; and no correlation between Lin \& Binns and Eberhart \& Russell. The most stable and productive genotypes commercial grains were: BRS Requinte and the breeding line CNFC 8075 for carioca type; BRS Supremo and BRS Campeiro for black type; and BRS Vereda for pink type.
\end{abstract}

Index terms: Phaseolus vulgaris, adaptability, grain yield.

\section{Introdução}

A obtenção de novas cultivares de feijoeiro-comum mais produtivas, menos sensíveis aos estresses bióticos e abióticos, e com características que atendam ao mercado consumidor, tem-se constituído, ao longo dos anos, em desafio contínuo dos programas de melhoramento genético. No Brasil, esse processo culminou com o lançamento total de 111 cultivares, 74 antes da Lei de Proteção de cultivares (período entre 1984 e 1997), e 37 após a promulgação da lei (1998 a
2004). Deste total, a Embrapa Arroz e Feijão foi responsável pelo desenvolvimento de 32 novas cultivares, de diversos tipos comerciais de grão, com média de 1,6 cultivar por ano. Nesse período, conseguiuse evoluir no melhoramento de algumas características, com destaque para a arquitetura da planta e resistência a algumas das principais doenças, aliadas à alta produtividade de grãos e ao tipo de grão comercial direcionado para o mercado interno. O estudo do impacto econômico indicou que para cada dólar investido no desenvolvimento de cultivares, houve o retorno de 
10 dólares (Alves et al., 2002), o que comprova a eficiência desse programa de melhoramento.

Os métodos e critérios de seleção no melhoramento do feijoeiro-comum, na Embrapa, enfatizam as demandas regionais e permitem o desenvolvimento de linhagens melhoradas, superiores às cultivares em uso. $\mathrm{Na}$ fase final dos programas de melhoramento, as linhagens são testadas em anos, épocas e locais diferentes, por meio de ensaios com repetições. A determinação do número de ambientes em que tais ensaios são conduzidos deve adequar-se à amostra representativa das condições de cultivo de cada região.

O feijoeiro-comum é cultivado em três safras, praticamente em todo o território nacional, durante o ano todo, está, portanto, sujeito às mais diferentes condições ambientais. Além disso, é utilizado por diversas categorias de agricultores, desde a agricultura de subsistência, com escasso ou sem nenhum uso de tecnologia, até o grande empresário agrícola, com utilização da mais moderna tecnologia de produção. A diversidade de condições ambientais em que o feijoeiro é cultivado requer que os ensaios sejam conduzidos em rede, em vários ambientes, para que se tenha uma boa estimativa da interação genótipo por ambiente, o que permite que se estime a estabilidade e adaptabilidade de genótipos elites, o que propicia maior segurança na indicação.

A identificação de cultivares, com maior estabilidade fenotípica, tem sido uma alternativa muito utilizada para atenuar os efeitos da interação genótipos com ambientes e tornar o processo de indicação de cultivares mais seguro. Existe uma série de métodos para esse fim, cada um deles tem suas vantagens e desvantagens, detalhadas em Lin et al. (1986). Na cultura do feijoeiro-comum, assim como em outras, esses métodos têm sido freqüentemente utilizados (Duarte \& Zimmerman, 1991; Abreu et al., 1992; Carbonell et al., 2001, 2004). As mais utilizadas são Lin \& Bins (Faria et al., 2005; Melo et al., 2005b) e Eberhart \& Russell (Duarte \& Zimmerman, 1991).

Um método que tem se destacado nos estudos de interação genótipos com ambientes é a análise AMMI (análise da interação multiplicativa e dos efeitos principais aditivos), pode auxiliar tanto na identificação de genótipos com alta produtividade e amplamente adaptados, como no zoneamento agronômico com a finalidade de recomendação regionalizada e seleção de locais testes (Gauch \& Zobel, 1996). Outra vantagem é a interpretação gráfica dos resultados das análises estatísticas por meio do procedimento biplot.
O objetivo deste trabalho foi avaliar a estabilidade e adaptabilidade de genótipos, do programa de melhoramento genético do feijoeiro-comum, da Embrapa Arroz e Feijão, pelos métodos AMMI, Lin \& Binns e Eberhart \& Russell, e comparar as estimativas de estabilidade obtidas por esses três métodos.

\section{Material e Métodos}

Foram analisados os dados relativos a 22 ensaios de teste de adaptação local (TAL), na época das águas (safra) e da seca (safrinha) dos anos de 2002, 2003 e 2004, nos municípios dos estados do Paraná (Ponta Grossa, Roncador, Pato Branco, Prudentópolis e Irati); de Santa Catarina (Abelardo Luz, Major Vieira, Concórdia e Campos Novos) e de São Paulo (Capão Bonito, Taquarituba e Itapeva). Foram seguidos os requisitos mínimos para determinação do valor de cultivo e uso, para a indicação de cultivares.

Os ensaios foram compostos de 20 genótipos, pertencentes aos grupos comerciais de grão preto, carioca, roxo, rosinha, jalo e rajado. As semeaduras foram realizadas nos meses de agosto a novembro, para a safra, e fevereiro para a safrinha, tendo-se colocado 15 sementes por metro, em linhas espaçadas de $50 \mathrm{~cm}$. Os experimentos foram instalados em delineamento de blocos completos ao acaso, com três repetições, em parcelas de quatro linhas de $4 \mathrm{~m}$, e somente as duas linhas internas foram utilizadas como área útil para coleta dos dados referentes à produtividade de grãos.

$\mathrm{Na}$ avaliação da reação a doenças, da arquitetura de planta e do acamamento, foi utilizada escala de notas de 1 a 9. Para antracnose, ferrugem, crestamento bacteriano, mancha-angular e oídio, foi utilizada uma escala em que o grau 1 é igual à ausência de sintomas, e a nota 9 é relativa a plantas próximas ao colapso ou mortas (Costa et al., 1990). Por ocasião da colheita, para arquitetura de planta, as notas foram de 1 (porte ereto, altura da extremidade da primeira vagem ao solo superior a $12 \mathrm{~cm}$, planta compacta sem guia) a 9 (planta bastante ramificada, vagens tocando no solo e excesso de guias) e, para acamamento foram de 1 (nenhuma planta acamada na parcela) a 9 (todas as plantas da parcela acamadas) (Costa et al., 1999). Os dados oriundos de notas não foram analisados estatisticamente, pois não atenderam às pressuposições para análise de variância. Entretanto, serviram como informação complementar às análises estatísticas para produtividade de grãos, que 
caracteriza, mais detalhadamente, o comportamento agronômico dos genótipos avaliados.

Inicialmente, foram realizadas as análises de variância individual e, posteriormente, a análise de variância conjunta. Reuniram-se todos os dados de produtividade de grãos dos ensaios, nos diferentes anos, épocas e locais, em que o modelo foi considerado fixo (Vencovsky \& Barriga, 1992). Para estudar o efeito da interação entre genótipos $\mathrm{x}$ ambientes, utilizou-se um procedimento alternativo, proposto por Cruz \& Castoldi (1991), que visa decompor a interação duas a duas, em partes simples e complexa.

Os parâmetros de adaptabilidade e estabilidade foram estimados com utilização dos métodos de Eberhart \& Russell (1966), Lin \& Binns (1988) e AMMI (Zobel et al., 1988). O método de Eberhart \& Russell (1966) se baseia na análise de regressão e tem como parâmetros de adaptabilidade: o coeficiente de regressão $\left(\beta_{1}\right)$, a produtividade média $\left(\beta_{0}\right)$ e a estabilidade dos genótipos avaliada pelo desvio de regressão $\left(\sigma_{\mathrm{d}}^{2}\right)$. O método de Lin \& Binns (1988) estima o parâmetro de estabilidade e adaptabilidade $\mathrm{P}_{\mathrm{i}}$, em que o genótipo mais estável é o que apresenta menor valor desta estimativa. No método AMMI (Zobel et al., 1988), o modelo empregado para descrever a reposta média de um genótipo i, num ambiente j, é:

$\mathrm{Y}_{\mathrm{ij}}=\mu+\mathrm{g}_{\mathrm{i}}+\mathrm{a}_{\mathrm{j}}+\sum_{\mathrm{k}=1}^{\mathrm{n}} \lambda_{\mathrm{k}} \gamma_{\mathrm{ik}} \alpha_{\mathrm{jk}}+\rho_{\mathrm{ij}}+\overline{\mathrm{e}}_{\mathrm{ij}}$ em que: $\mathrm{Y}_{\mathrm{ij}}$ é a resposta média do genótipo i ( $\mathrm{i}=1,2, \ldots$, $\mathrm{G}$ genótipos), no ambiente $\mathrm{j}(\mathrm{j}=1,2, \ldots, \mathrm{A}$ ambientes); $\mu$ é a média geral dos ensaios; $g_{i}$ é o efeito do genótipo i; $\mathrm{a}_{\mathrm{j}}$ é o efeito do ambiente j; $\lambda_{\mathrm{k}}$ é o k-ésimo valor singular (escalar) da matriz de interações original (denotada por $\mathrm{GA}) ; \gamma_{\mathrm{ik}}$ é o elemento correspondente ao i-ésimo genótipo, no k-ésimo vetor singular coluna da matriz GA; $\alpha_{j k}$ é o elemento correspondente ao j-ésimo ambiente, no k-ésimo vetor singular linha da matriz $\mathrm{GA} ; \rho_{\mathrm{ij}}$ é o ruído associado ao termo $(\mathrm{ga})_{\mathrm{ij}}$, da interação clássica do genótipo i com o ambiente $\mathrm{j}$; $\overline{\mathrm{e}}_{\mathrm{ij}}$ é o erro experimental médio.

$\mathrm{O}$ termo $(\mathrm{ga})_{\mathrm{ij}}$ de um modelo de análise conjunta tradicional é modelado por:

$(\mathrm{ga})_{\mathrm{ij}}=\sum_{\mathrm{k}=1}^{\mathrm{n}} \lambda_{\mathrm{k}} \gamma_{\mathrm{ik}} \alpha_{\mathrm{ik}}+\rho_{\mathrm{ij}}$, em que: $\rho_{\mathrm{ij}}=\sum_{\mathrm{k}=\mathrm{n}+1}^{\mathrm{p}} \lambda_{\mathrm{k}} \gamma_{\mathrm{ik}} \alpha_{\mathrm{jk}}$,

e p é o posto da matriz GA. Os termos $\lambda_{\mathrm{k}}, \gamma_{\mathrm{ik}}$ e $\alpha_{\mathrm{jk}}$ resultam da chamada decomposição por valores singulares (DVS) da matriz de interações clássica: $\mathrm{GA}_{(\mathrm{g} \times \mathrm{a})}=\left[(\mathrm{ga})_{\mathrm{ij}}\right]$, com: $\left(\widehat{g a a ~}_{)_{i j}}=\mathrm{Y}_{\mathrm{ij}}-\overline{\mathrm{Y}}_{\mathrm{i}}-\overline{\mathrm{Y}}_{\mathrm{j}}+\overline{\mathrm{Y}}_{\mathrm{Y}}\right.$,

em que: $\bar{Y}_{\mathrm{i}}$ é a média do genótipo $\mathrm{i}$; $\overline{\mathrm{Y}}_{\mathrm{j}}$ é a média do ambiente $\mathrm{j}$; $\overline{\mathrm{Y}}$ é a média geral dos ensaios. A obtenção da DVS de uma matriz, nesse tipo de aplicação, é des- crita por Duarte \& Vencovsky (1999). Esses autores comentaram que, no modelo AMMI, o efeito da interação do genótipo i com o ambiente $\mathrm{j}$ é descrito como uma soma de $\mathrm{n}$ parcelas, cada uma resultante da multiplicação de $\lambda_{\mathrm{k}}$ expresso na mesma unidade de $\mathrm{Y}_{\mathrm{ij}}$ por efeitos de escala (adimensionais) genotípica $\left(\gamma_{\mathrm{ik}}\right)$ e ambiental $\left(\alpha_{\mathrm{jk}}\right)$. O termo $\lambda_{\mathrm{k}}$ traz informação relativa à variação resultante da interação GxA, na k-ésima dessas parcelas. Semelhantemente à análise de componentes principais (ACP), essas sucessivas parcelas captam porções cada vez menores da variação presente na matriz GA $\left(1_{1}^{2} \geq 1_{2}^{2} \geq \ldots \geq 1_{p}^{2}\right)$, isto é, a soma de quadrados $S_{\mathrm{GxA}}$ tradicional. Assim, a análise busca recuperar uma parcela determinística da matriz denominada padrão, descartando-se outra denominada ruído $\left(\rho_{\mathrm{ij}}\right)$. O ajuste desse modelo foi implementado por meio de rotina computacional do SAS, desenvolvida e descrita por Duarte \& Vencovsky (1999).

Para avaliar o grau de associação, entre os métodos de estabilidade analisados, foi estimado o coeficiente de correlação de Spearman entre os métodos, com base na ordem de classificação genotípica, de acordo com o parâmetro do método (Silva \& Duarte, 2006).

\section{Resultados e Discussão}

$\mathrm{Na}$ análise de variância da produtividade de grãos dos 20 genótipos avaliados no teste de adaptação local (TAL), nos estados do Paraná, Santa Catarina e São Paulo, obtiveram-se efeitos significativos de cultivares, ambientes e interação genótipos com ambientes.

$\mathrm{O}$ efeito de genótipos indica a presença de variabilidade para a seleção, o de ambientes indica a variabilidade entre locais, anos e épocas de cultivo, fato importante para tornar o processo de indicação de cultivares mais eficiente, e a ocorrência de interação indica resposta diferencial dos genótipos às mudanças de ambiente. As médias dos ambientes tiveram amplitude de variação elevada, $26,8 \%$ superior à média geral. Essa variação ocorreu em razão das condições edafoclimáticas de cada ambiente (local, época e ano) e indica a necessidade do estudo da estabilidade fenotípica destes genótipos (Ramalho et al., 1993).

As novas cultivares de feijão com tipo de grão preto, desenvolvidas pela Embrapa Arroz e Feijão, BRS Campeiro (2.723 $\mathrm{kg} \mathrm{ha}^{-1}$ ) e BRS Supremo (2.510 $\left.\mathrm{kg} \mathrm{ha}^{-1}\right)$, destacaram-se em comparação com as testemunhas Uirapuru e BRS Valente (Tabela 1). 
A linhagem de grão carioca, do programa de melhoramento da Embrapa Arroz e Feijão, CNFC 8075, destacou-se com $2.639 \mathrm{~kg} \mathrm{ha}^{-1}$, e a cultivar BRS Requinte com $2.497 \mathrm{~kg} \mathrm{ha}^{-1}$, em comparação à cultivar Pérola. Para o tipo de grão rajado, a cultivar BRS Radiante, com $2.452 \mathrm{~kg} \mathrm{ha}^{-1}$, indicada para o Distrito Federal e os estados de Goiás, Minas Gerais e Mato Grosso do Sul, foi superior às testemunhas do mesmo tipo comercial de grão, Iraí e Diacol Calima. Em relação ao tipo de grão jalo, a cultivar Jalo Precoce, com $2.138 \mathrm{~kg} \mathrm{ha}^{-1}$, indicada para o Distrito Federal, Goiás, Bahia, Minas Gerais, Mato Grosso e Mato Grosso do Sul, foi superior à testemunha 'Goiano Precoce'. A cultivar BRS Vereda, com $2.548 \mathrm{~kg} \mathrm{ha}^{-1}$, de tipo de grão rosinha, por falta de testemunha comercial desse tipo de grão, foi comparada à testemunha de grão roxo (Roxo 90), e superou este genótipo. A BRS Vereda também foi superior à linhagem CNFR 7847 (grão roxo), mas inferior à cultivar Vermelho 2157, que possui grãos vermelhos, mas compete com as cultivares de grão rosinha, no mercado de feijão com grãos diferenciados.

Com relação as avaliações de arquitetura e acamamento, observou-se entre as cultivares de grão tipo carioca, que a BRS Horizonte destacou-se entre as demais por apresentar arquitetura de planta ereta e tolerância ao acamamento, semelhantemente às cultivares do grupo preto, que tradicionalmente apresentam melhor arquitetura de planta (Tabela 1), o que concorda com Melo et al. (2005b). Na maioria das situações, os agricultores buscam cultivares com arquitetura de plantas eretas (vagens que não tocam o solo, guias curtas e ramificações fechadas) e tolerantes ao acamamento, o que propicia a colheita mecânica com baixo índice de perdas, melhor qualidade do grão e menor incidência de doenças, em razão da melhor aeração na lavoura e ao não contato das vagens com o solo, principalmente quando a colheita coincide com o período de chuvas. Essas novas demandas dos produtores de feijão indicam que a cultivar BRS Horizonte, que possui arquitetura de planta ereta e baixo acamamento, poderá ter sucesso no mercado, mesmo com produtividade média um pouco abaixo de outras cultivares (Tabela 1).

Com relação a reação às doenças (Tabela 1), no grupo com tipo de grão carioca, as notas são evidências da resistência à antracnose e ferrugem pelas cultivares BRS Requinte e BRS Horizonte. A

Tabela 1. Médias dos genótipos de feijoeiro-comum para produtividade de grão, notas ${ }^{(1)}$ de arquitetura de plantas (ARQ), acamamento (ACA), reação à antracnose (ANT), ferrugem (FE), crestamento bacteriano comum (CBC), mancha-angular (MA) e oídio (OI), em municípios dos estados de São Paulo, Paraná e Santa Catarina, na safra e na safrinha de 2002,2003 e 2004.

\begin{tabular}{|c|c|c|c|c|c|c|c|c|c|}
\hline \multirow[t]{2}{*}{ Cultivares/linhagens } & \multirow{2}{*}{$\begin{array}{l}\text { Tipo comercial de } \\
\text { grão }\end{array}$} & \multirow{2}{*}{$\begin{array}{l}\text { Produtividade } \\
\left(\mathrm{kg} \mathrm{ha}^{-1}\right)^{(2)}\end{array}$} & \multirow[t]{2}{*}{ ARQ } & \multirow[t]{2}{*}{$\mathrm{ACA}$} & \multicolumn{5}{|c|}{ Reação a doenças } \\
\hline & & & & & ANT & $\mathrm{FE}$ & $\mathrm{CBC}$ & MA & $\mathrm{OI}$ \\
\hline CNFC 8075 & Carioca & $2.639 \mathrm{a}$ & 5 & 6 & 4 & 3 & 4 & 2 & 2 \\
\hline BRS Requinte & Carioca & $2.497 \mathrm{~b}$ & 5 & 7 & 1 & 2 & 3 & 2 & 1 \\
\hline IAPAR 81 & Carioca & $2.468 \mathrm{~b}$ & 4 & 5 & 2 & 4 & 4 & 3 & 2 \\
\hline BRS Horizonte & Carioca & $2.361 \mathrm{c}$ & 4 & 4 & 1 & 1 & 4 & 4 & 3 \\
\hline Pérola & Carioca & $2.359 \mathrm{c}$ & 5 & 6 & 5 & 3 & 3 & 3 & 2 \\
\hline BRS Campeiro & Preto & $2.723 a$ & 4 & 4 & 2 & 2 & 3 & 4 & 2 \\
\hline BRS Supremo & Preto & $2.510 \mathrm{~b}$ & 4 & 3 & 2 & 1 & 4 & 2 & 1 \\
\hline Uirapuru & Preto & $2.462 \mathrm{~b}$ & 4 & 4 & 3 & 2 & 4 & 2 & 3 \\
\hline BRS Valente & Preto & $2.359 \mathrm{c}$ & 4 & 4 & 2 & 4 & 5 & 2 & 3 \\
\hline CNFP 7726 & Preto & $2.272 \mathrm{c}$ & 5 & 5 & 4 & 4 & 4 & 2 & 2 \\
\hline Jalo Precoce & Jalo & $2.138 \mathrm{~d}$ & 5 & 4 & 1 & 1 & 2 & 3 & 5 \\
\hline Jalo EEP 558 & Jalo & $2.007 \mathrm{~d}$ & 5 & 6 & 1 & 3 & 4 & 2 & 6 \\
\hline Goiano Precoce & Jalo & $1.679 \mathrm{e}$ & 6 & 4 & 2 & 2 & 4 & 4 & 4 \\
\hline BRS Radiante & Rajado & $2.452 \mathrm{~b}$ & 5 & 4 & 2 & 2 & 4 & 4 & 1 \\
\hline Iraí & Rajado & $2.219 \mathrm{c}$ & 5 & 4 & 1 & 2 & 4 & 3 & 4 \\
\hline Diacol Calima & Rajado & $2.020 \mathrm{~d}$ & 4 & 2 & 1 & 2 & 3 & 3 & 7 \\
\hline Vermelho 2157 & Vermelho & $2.620 \mathrm{a}$ & 6 & 7 & 2 & 2 & 3 & 2 & 3 \\
\hline BRS Vereda & Rosinha & $2.548 \mathrm{~b}$ & 4 & 5 & 1 & 1 & 3 & 2 & 1 \\
\hline CNFR 7847 & Roxo & $2.070 \mathrm{~d}$ & 6 & 8 & 1 & 3 & 5 & 3 & 1 \\
\hline Roxo 90 & Roxo & $1.701 \mathrm{e}$ & 6 & 6 & 4 & 5 & 6 & 3 & 4 \\
\hline Média & & 2.305 & 4,8 & 4,9 & 2,1 & 2,5 & 3,8 & 2,8 & 2,9 \\
\hline
\end{tabular}

${ }^{(1)}$ Notas: 1, fenótipo mais desejável; 9, menos desejável. ${ }^{(2)}$ Médias seguidas por letras iguais não diferem entre si pelo teste Scott-Knott, a $5 \%$ de probabilidade; coeficiente de variação: $17,3 \%$. 
BRS Requinte também apresentou resistência ao oídio, assim como a BRS Supremo, BRS Radiante e a BRS Vereda. Resultados semelhantes foram encontrados por Costa et al. (2004), Faria et al. (2004) e Melo et al. (2005a). Em geral, as cultivares recémlançadas apresentaram nível de resistência a doenças superior às antigas, o que pode ser exemplificado pela suscetibilidade da cultivar Pérola à antracnose e da cultivar BRS Valente ao crestamento bacteriano comum, e pelo comportamento apresentado pelas cultivares BRS Requinte e BRS Vereda, com notas médias inferiores à média geral para reação a todas as doenças avaliadas. No entanto, todos os genótipos apresentaram ampla variação de reação às doenças nos ambientes testados. Assim, parte da interação genótipos com ambientes, obtida neste estudo, ocorreu em razão da diferença na incidência e severidade das doenças nos diversos ambientes, ocasionada por variações nas condições climáticas e nas populações de patótipos, assim como observado por Melo et al. (2002) para oídio e mancha-angular.

A significância da interação genótipos com ambientes indica a necessidade de se identificarem as cultivares com adaptação mais específica, ou que sejam menos afetadas pela variação dos ambientes (Ramalho et al., 1993). De um total de 231 combinações de ambientes dois a dois, a interação simples ocorreu em $42(18,2 \%)$ e a interação complexa predominou em $189(81,8 \%)$ das combinações. A ocorrência da interação genótipos com ambientes, do tipo complexa, foi relatada para a produtividade de grãos em outros trabalhos com feijoeiro-comum (Teixeira, 2004; Amaro, 2006)

Segundo Silva \& Duarte (2006), os métodos Eberhart \& Russell (1966) e AMMI (Zobel et al., 1988) complementam-se, principalmente, nos casos onde a interação genótipos com ambientes é complexa. Esses autores mostraram que a combinação dos dois métodos pode ser eficiente, pois encontraram fraca associação, entre eles, e correlações significativas com os outros estudados. O método de Lin \& Binns (1988) também foi recomendado por Silva \& Duarte (2006), para agregar informações às obtidas pelo método de Eberhart \& Russell (1966).

A avaliação dos genótipos pelo método de Eberhart $\&$ Russel mostrou que as cultivares Goiano Precoce e Pérola apresentaram adaptação específica a ambientes desfavoráveis $\left(\beta_{\mathrm{i}}<1\right)$, e a cultivar Vermelho 2157 a ambientes favoráveis $\left(\beta_{\mathrm{i}}>1\right)$ (Tabela 2). Os demais genótipos apresentaram adaptabilidade geral, com $\beta_{\mathrm{i}}$ estatisticamente igual à unidade $\left(\beta_{\mathrm{i}}=1\right)$, porém, apenas as cultivares BRS Requinte, BRS Horizonte, BRS Supremo, Jalo EEP 558 e a linhagem CNFR 7847 mostraram-se estáveis (desvio de regressão nãosignificativo); somente as três primeiras apresentaram rendimentos acima da média geral dos genótipos e estão recomendadas para cultivo nos estados de São Paulo, Paraná e Santa Catarina.

Segundo Faria et al. (2004), a cultivar BRS Requinte é do grupo carioca, apresenta reduzido escurecimento do tegumento do grão, durante o armazenamento, associado à boa qualidade culinária com tempo de cocção reduzido. É uma das poucas cultivares de feijão que pode ser armazenada, sem sofrer depreciação de seu valor comercial, pois não apresenta escurecimento dos grãos nos cinco primeiros meses de armazenamento.

Segundo Melo et al. (2005b), a cultivar BRS Horizonte possui tipo comercial de grão carioca, porte ereto, ciclo normal (75 a 85 dias) e massa de 100 grãos de $28 \mathrm{~g}$.

Tabela 2. Estimativas dos parâmetros de estabilidade e adaptabilidade, método de Eberhart \& Russell (1966), para genótipos de feijoeiro-comum, avaliados em 22 ambientes nas safras de 2002, 2003 e 2004, nos estados de São Paulo, Paraná e Santa Catarina.

\begin{tabular}{lclcl}
\hline Genótipos & Médias & $\hat{\beta}_{i}^{(1)}$ & $\hat{\sigma}_{\mathrm{di}}^{2(2)}$ & $\mathrm{R}^{2}(\%)$ \\
\hline BRS Campeiro & $2.723 \mathrm{a}$ & 0,927 & $63.821,5$ & 82,53 \\
CNFC 8075 & $2.639 \mathrm{a}$ & 1,053 & $103.836,9$ & 81,95 \\
Vermelho 2157 & $2.620 \mathrm{a}$ & $1,194^{* *}$ & $107.135,6$ & 85,13 \\
BRS Vereda & $2.548 \mathrm{~b}$ & 1,061 & $37.760,8$ & 88,84 \\
BRS Supremo & $2.510 \mathrm{~b}$ & 0,967 & $30.670,9^{\mathrm{ns}}$ & 87,76 \\
BRS Requinte & $2.497 \mathrm{~b}$ & 0,986 & $24.573,7^{\mathrm{ns}}$ & 88,95 \\
IAPAR 81 & $2.468 \mathrm{~b}$ & 1,085 & $170.237,6$ & 77,24 \\
Uirapuru & $2.462 \mathrm{~b}$ & 1,025 & $153.072,6$ & 76,62 \\
BRS Radiante & $2.452 \mathrm{~b}$ & 1,032 & $124.272,8$ & 79,44 \\
BRS Horizonte & $2.361 \mathrm{c}$ & 1,032 & $19.919,5^{\mathrm{ns}}$ & 90,35 \\
Pérola & $2.359 \mathrm{c}$ & $0,807 *$ & $418.453,7$ & 47,05 \\
BRS Valente & $2.359 \mathrm{c}$ & 1,071 & $100.621,1$ & 82,76 \\
CNFP 7726 & $2.272 \mathrm{c}$ & 0,991 & $39.576,6$ & 87,21 \\
Iraí & $2.219 \mathrm{c}$ & 1,037 & $140.459,8$ & 78,13 \\
Jalo Precoce & $2.138 \mathrm{~d}$ & 0,946 & $51.254,6$ & 84,64 \\
CNFR 7847 & $2.070 \mathrm{~d}$ & 0,995 & $21.884,7^{\mathrm{ns}}$ & 89,45 \\
Diacol Calima & $2.020 \mathrm{~d}$ & 1,031 & $86.086,7$ & 83,1 \\
Jalo EEP 558 & $2.007 \mathrm{~d}$ & 1,067 & $26.474,3^{\mathrm{ns}}$ & 90,19 \\
Roxo 90 & $1.701 \mathrm{e}$ & 0,916 & $88.972,5$ & 79,16 \\
Goiano Precoce & $1.679 \mathrm{e}$ & $0,777^{* *}$ & $199.132,3$ & 60,62 \\
\hline
\end{tabular}

${ }^{(1)} \mathrm{H}_{0}: \beta_{\mathrm{i}}=1 .{ }^{(2)} \mathrm{H}_{0}: \hat{\sigma}_{\mathrm{di}}^{2}=0$. ns Não-significativo. * e ${ }^{* *}$ Significativo a $5 \mathrm{e}$ $1 \%$ de probabilidade, respectivamente, pelo teste $\mathrm{t}$. 
A cultivar BRS Supremo apresenta porte ereto, ciclo normal (80 a 86 dias) e massa de 100 grãos de $25 \mathrm{~g}$ (Costa et al., 2004).

Os resultados das análises de estabilidade e adaptabilidade, obtidos pelo método de Lin \& Binns estão apresentados na Tabela 3. Observa-se que a cultivar BRS Campeiro foi a que apresentou o menor valor de $\mathrm{P}_{\mathrm{i}}$ entre todos os genótipos, o que evidencia que essa cultivar apresenta, além de alta produtividade média, maior estabilidade nas condições de cultivo do Centro-Sul do Brasil. Para os ambientes favoráveis, a linhagem CNFC 8075 e a cultivar Vermelho 2157 foram as que mais se destacaram, portanto, são recomendadas para as condições de alto nível tecnológico. Dentro do tipo de grão preto, a cultivar BRS Campeiro foi a mais adequada para as condições de baixa e alta tecnologia e superou, em todas as situações, as testemunhas com esse tipo de grão, em adaptabilidade e estabilidade de produção. A cultivar BRS Supremo também se destacou, principalmente em ambientes desfavoráveis, o que coincide com o resultado obtido por Melo et al. (2005a). No grupo carioca, a cultivar BRS Requinte foi a mais adaptada a condições de baixo nível tecnológico, com máxima vantagem competitiva.

$\mathrm{Na}$ análise AMMI obtiveram-se 19 componentes (IPCA). Segundo Chaves (2001), o modelo mais adequado é aquele que associa significância para os eixos (IPCA) com não significância para o resíduo (ruído), com uma porção não muito elevada de graus de liberdade. Neste trabalho, o modelo mais adequado seria AMMI 6, a $1 \%$ de probabilidade. Uma observação importante é com relação à contribuição relativa de cada componente principal (eixo), na variação total entre os genótipos nos diferentes ambientes. O primeiro eixo explicou $26,6 \%$ da soma de quadrados da interação; os eixos 1 e 2 explicaram, em conjunto, $45,9 \%$, enquanto os três primeiros eixos contribuíram com 59\% dessa variação. Esses resultados são coincidentes com os de Carbonell et al. (2004), que avaliaram linhagens e cultivares de feijoeiro no Estado de São Paulo.

A representação gráfica desses resultados é difícil, bem como a associação dos escores dos eixos IPCA 3 e superiores, com atributos identificáveis dos genótipos e dos ambientes. Segundo Gauch (1988), os primeiros eixos AMMI captam maior porcentagem do desempenho real ("padrão") e, com subseqüente acumulação de dimensões (eixos), ocorre diminuição na porcentagem de "padrão" e um acréscimo de informações imprecisas ("ruídos"). Com isso, apesar da seleção de um só eixo, com pequena porção da $\mathrm{SQ}_{\mathrm{GxA}}$ original, espera-se captar maior porcentagem do "padrão".

Foram utilizados, para ilustrar o efeito de cada genótipo e ambiente, os gráficos biplot AMMI 1 (médias x

Tabela 3. Estimativas da estabilidade e adaptabilidade $\left(\mathrm{P}_{\mathrm{i}}\right)$, de acordo com o método de Lin \& Binns (1988), para genótipos de feijoeiro-comum, avaliados nas safras de 2002, 2003 e 2004, em 22 ambientes nos estados de São Paulo, Paraná e Santa Catarina.

\begin{tabular}{|c|c|c|c|c|c|}
\hline Genótipos & $P_{i}$ geral & Genótipos & $P_{i}$ fav. & Genótipos & $\mathrm{P}_{\mathrm{i}}$ desf. \\
\hline BRS Campeiro & 123.427 & Vermelho 2157 & 66.816 & BRS Campeiro & 96.356 \\
\hline CNFC 8075 & 156.222 & CNFC 8075 & 110.134 & BRS Requinte & 163.804 \\
\hline Vermelho 2157 & 171.367 & BRS Campeiro & 181.438 & CNFC 8075 & 177.730 \\
\hline BRS Vereda & 211.233 & BRS Vereda & 200.506 & BRS Supremo & 179.710 \\
\hline BRS Supremo & 213.866 & Uirapuru & 261.004 & BRS Vereda & 216.240 \\
\hline BRS Requinte & 214.477 & BRS Radiante & 261.859 & Vermelho 2157 & 220.158 \\
\hline Iapar 81 & 269.393 & IAPAR 81 & 285.658 & IAPAR 81 & 261.803 \\
\hline BRS Horizonte & 304.532 & BRS Requinte & 323.063 & Pérola & 271.511 \\
\hline BRS Radiante & 319.538 & BRS Horizonte & 385.043 & BRS Valente & 297.148 \\
\hline BRS Valente & 344.708 & BRS Valente & 446.623 & Uirapuru & 308.274 \\
\hline CNPC 7726 & 380.015 & CNFP 7726 & 480.613 & CNFP 7726 & 333.069 \\
\hline Pérola & 487.894 & Iraí & 533.830 & BRS Radiante & 346.456 \\
\hline Irai & 518.745 & Jalo Precoce & 593.713 & Jalo Precoce & 511.662 \\
\hline Jalo Precoce & 537.769 & JALO EEP 558 & 683.634 & Iraí & 511.705 \\
\hline Jalo EEP 558 & 669.358 & Diacol Calima & 724.457 & JALO EEP 558 & 662.696 \\
\hline Diacol Calima & 706.185 & Pérola & 951.572 & Diacol Calima & 697.658 \\
\hline Roxo 90 & 1.068 .715 & Roxo 90 & 1.449 .520 & Roxo 90 & 891.007 \\
\hline Goiano Precoce & 1.208 .557 & Goiano Precoce & 1.548 .375 & Goiano Precoce & 1.049 .976 \\
\hline
\end{tabular}


IPCA 1) e AMMI 2 (IPCA 1 e IPCA 2) (Figura 1). Na Figura $1 \mathrm{~A}$, a abscissa indica os efeitos principais (médias), e a ordenada os efeitos da interação (IPCA 1). Quanto mais distante da origem do eixo AMMI de interação (AMMI 1), maior é a contribuição para a interação. Nesse caso, a linhagem CNFR 7847 (G10) e as cultivares BRS Supremo (G8), BRS Campeiro (G9) e BRS Vereda (G3) contribuíram menos para a interação, e foram consideradas, por esse método, as mais estáveis agronomicamente. Todas essas cultivares apresentaram produtividade de grãos acima da média geral dos genótipos, o que significa que elas expressam adaptabilidade geral. A cultivar mais instável foi Goiano Precoce (G12), que possui hábito de crescimento determinado, grão tipo jalo, porte ereto e precoce, desenvolvida pelo Instituto Agronômico (IAC) e lançada em 1966, e é recomendada para os Estados de São Paulo, Minas Gerais e Paraná.

Em relação aos ambientes, destacam-se, com menor contribuição para interação, os ambientes A7 (Abelardo Luz, safrinha 2003), A9 (Campos Novos, safrinha 2003) e A3 (Pato Branco, safra 2003). Os ambientes mais discrepantes foram A8 (Roncador, safrinha 2003), A15 (Capão Bonito, safra 2003), A17 (Prudentopólis, safra 2003) e A22 (Ponta Grossa, safrinha 2003). O ambiente A8 apresentou a menor média dos genótipos $\left(998 \mathrm{~kg} \mathrm{ha}^{-1}\right)$, e o A15 a maior média $\left(3920 \mathrm{~kg} \mathrm{ha}^{-1}\right)$, e podem ser considerados exemplos de ambiente desfavorável e favorável, respectivamente. Os locais A20 e A21 foram muito semelhantes, representam o plantio na safra de 2003 (outubro) nos locais de Ponta Grossa e Abelardo Luz. Essa informação é importante, uma vez que se pode substituir um desses locais por outro mais representativo da região, em que as cultivares serão recomendadas.

Na Figura 1 B, novamente a linhagem CNFR 7847 (G10) e a cultivar BRS Supremo (G8) foram as mais estáveis. Combinações de genótipos e ambientes com escores IPCA de mesmo sinal têm interações específicas positivas; observa-se que esta relação ocorreu entre Iraí (G14) e A11 (Major Vieira, safrinha 2004), Jalo EEP 558 (G15) e A5 (Campos Novos, safrinha 2003), CNPR 7847 (G10) e BRS Vereda (G 3) e A10 (Abelardo Luz, safrinha 2004), BRS Supremo (G8) e A4 (Ponta Grossa, safra 2002), Diacol Calima (G11) e A13 (Ponta Grossa, safrinha 2004), e Vermelho 2157 (G20) e A14 (Taquarituba, safra 2003). A adaptação específica indica maior média de produtividade de grãos em um determinado ambiente, vantajoso, principalmente, para a cultura do feijoeiro-comum que é plantado em diferentes épocas. A identificação de genótipos, com adaptação específica a uma região, pode levar a recomendação mais precisa das cultivares, com melhor
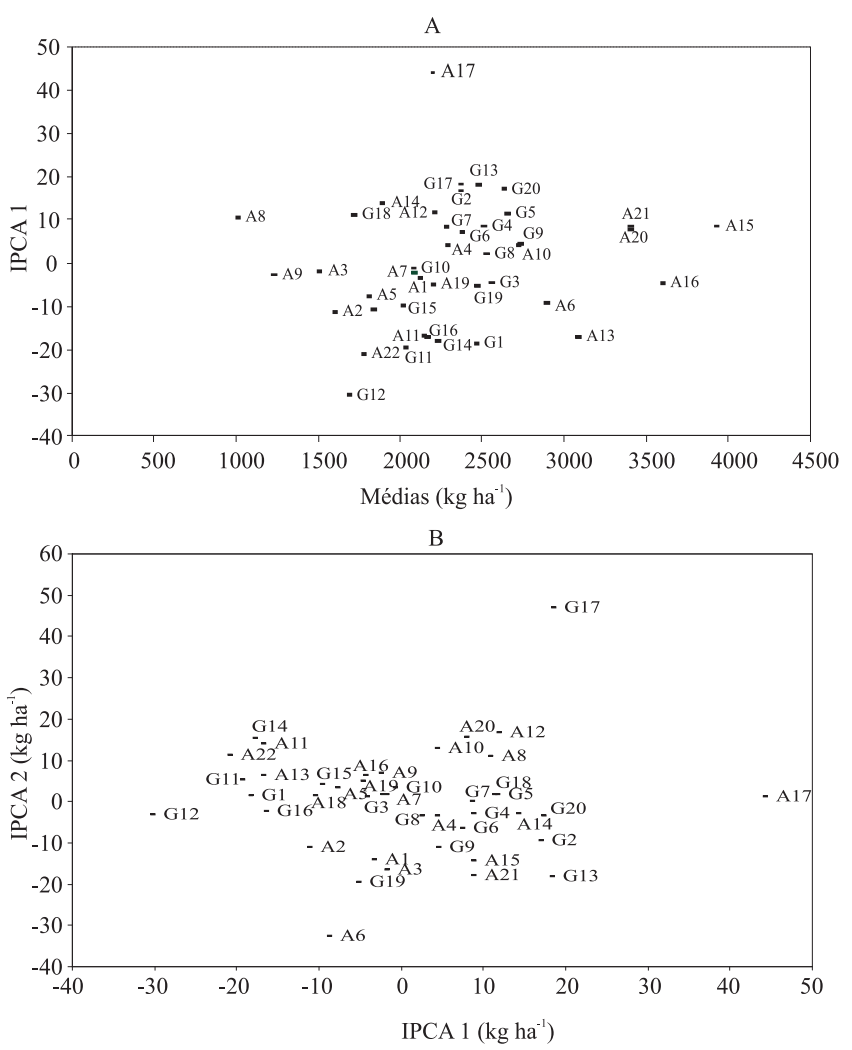

Figura 1. Análise biplot para dados de IPCA 1 x médias (A) e IPCA 1 x IPCA 2 (B), para produtividade de grãos em genótipos de feijoeiro-comum (kg ha-1), avaliados em 2002, 2003 e 2004 em São Paulo, Paraná e Santa Catarina. Genótipos: G1, BRS Campeiro; G2, BRS Valente; G3, BRS Vereda; G4, BRS Requinte; G5, CNFC 8075; G6, BRS Horizonte; G7, CNFP 7726; G8, BRS Supremo; G9, BRS Campeiro; G10, CNFR 7847; G11, Diacol Calima; G12, Goiano Precoce; G13, IAPAR 81; G14, Iraí; G15, Jalo EEP 558; G16, Jalo Precoce; G17, Pérola; G18, Roxo 90; G19, Uirapuru; G20, Vermelho 2157. Ambientes: A1, Prudentopólis/2002;A2, Campos Novos/2002; A3, Pato Branco/2002; A4, Ponta Grossa/2002; A5, Campos Novos/2003; A6, Aberlardo Luz/2002; A7, Aberlardo Luz/ 2003; A8, Roncador/2003; A9, Campos Novos/2003; A10, Abelardo Luz/2004; A11, Major Vieira/2004; A12, Prudentópolis/2004; A13, Ponta Grossa/2004; A14, Taquarituba/2003; A15, Capão Bonito/2003; A16, Itapeva/2003; A17, Prudentopólis/2003; A18, Major Vieira/2003; A19, Concórdia/2003; A20, Ponta Grossa/2003; A21, Abelardo Luz/2003; A22, Ponta Grossa/2003. 
aproveitamento do seu potencial genético, pois capitaliza a interação genótipos com ambientes a seu favor (Ramalho et al., 1993).

As estimativas do coeficiente de correlação de Spearman entre os métodos indicaram baixa associação entre AMMI e Lin \& Binns $(r=0,39)$, e AMMI e Eberhart \& Russell $(\mathrm{r}=0,40)$ e ausência de correlação entre Lin \& Binns e Eberhart \& Russell $\left(r=0,29^{\text {ns }}\right)$ que, neste último caso, também foi observado por Carbonell et al. (2001) em feijeiro-comum. Os genótipos que se destacaram quanto à estabilidade, pelos métodos de Eberhart \& Russell e AMMI, foram a linhagem CNFR 7847 e a cultivar BRS Supremo, embora a produtividade da primeira tenha sido inferior à média dos genótipos. No método de Lin \& Binns, os genótipos mais estáveis, na análise geral e em ambientes favoráveis, foram a BRS Campeiro, Vermelho 2157 e a linhagem CNFC 8075, que foram também os mais produtivos. 'Goiano Precoce' e 'Pérola' apresentaram adaptação a ambientes desfavoráveis, pelo método de Eberhart \& Russell, e BRS Campeiro e BRS Requinte, pelo método de Lin \& Binns. Os valores de $\mathrm{P}_{\mathrm{i}}$ geral e as médias dos genótipos apresentaram correlação de $-0,97$, o que indica que os genótipos mais produtivos estiveram, na maioria das vezes, entre os mais estáveis. Essa alta correlação entre média e estabilidade é uma característica do método de Lins \& Binns, pois associa estabilidade com a capacidade dos genótipos de apresentar o menor desvio em relação ao máximo, em todos os ambientes do estudo. Essa é considerada a maior vantagem desse método, pois consegue identificar os genótipos mais estáveis sempre entre os mais produtivos, como observado também por Carbonell et al. (2001), em estudo de avaliação de estabilidade em feijoeiro.

Os resultados encontrados, para os diferentes métodos avaliados, concordam com os obtidos por Silva \& Duarte (2006) e confirmam que os métodos de Eberhart \& Russell, Lin \& Binns e AMMI são pouco correlacionados e, portanto, fornecem informações complementares. Assim, a utilização simultânea desses três métodos gera estimativas, com abordagens diferenciadas, do processo de interação entre genótipos e ambientes.

\section{Conclusões}

1. Existe predominância da interação genótipos com ambientes do tipo complexa, na avaliação de genótipos de feijoeiro-comum em diferentes épocas, anos e locais.

2. Os genótipos mais estáveis e produtivos, para tipo de grão comercial carioca, são as cultivares BRS Requinte e a linhagem CNFC 8075; para tipo de grão comercial preto, as cultivares BRS Supremo e BRS Campeiro; e para tipo de grão comercial rosinha, a cultivar BRS Vereda.

3. Os três métodos fornecem informações complementares, e os métodos de Lin \& Binns e Eberhart \& Russell são os que apresentam resultados mais discrepantes.

\section{Referências}

ABREU, A.F.B.; RAMALHO, M.A.P.; SANTOS, J.B. dos. Desempenho e estabilidade fenotípica de cultivares de feijão em algumas localidades do Estado de Minas Gerais no período de 19891991. Ciência e Prática, v.16, p.18-24, 1992.

ALVES, E.R.A.; MAGALHÃES, M.C.; GUEDES, P.P. Calculando e atribuindo os benefícios da pesquisa de melhoramento de variedades: o caso Embrapa. Brasília: Embrapa Informação Tecnológica, 2002. 248p.

AMARO, G.B. Seleção recorrente fenotípica no feijoeiro visando resistência a Phaeoisariopsis griseola. 2006. 90p. Tese (Doutorado) - Universidade Federal de Lavras, Lavras.

CARBONELL, S.A.M.; AZEVEDO FILHO, J.A.; DIAS, L.A.S.; GARCIA, A.A.F.; MORAIS, L.K. Common bean cultivars and lines interactions with environments. Scientia Agricola, v.61, p.169177, 2004.

CARBONELL, S.A.M.; AZEVEDO FILHO, J.A.; DIAS, L.A.S.; GONÇALVES, C.; ANTONIO, C.B. Adaptabilidade e estabilidade de produção de cultivares e linhagens de feijoeiro no Estado de São Paulo. Bragantia, v.60, p.69-77, 2001.

CHAVES, L.J. Interação de genótipos com ambientes. In: NASS, L.L.; VALOIS, A.C.C.; MELO, I.S.; VALADARES-INGLIS, M.C. (Ed.). Recursos genéticos e melhoramento de plantas. Rondonopólis: Fundação MT, 2001. p.675-712.

COSTA, J.G.C.; FARIA, L.C.; RAVA, C.A.; DEL PELOSO, M.J.; MELO, L.C.; CABRERA DIAZ, J.L.; FARIA, J.C.; SILVA, H.T.; SARTORATO, A.; BASSINELO, P.Z.; ZIMMERMANN, F.J.P. BRS Supremo: cultivar de grão preto de feijoeiro-comum, de porte ereto, indicada para as regiões Sul e Centro-Oeste. Santo Antônio de Goiás: Embrapa Arroz e Feijão, 2004. 2p. (Embrapa Arroz e Feijão. Comunicado técnico, 87).

COSTA, J.G.C.; RAVA, C.A.; SARTORATO, A.; MORI, E. Linhagens de feijão do grupo preto com resistência conjunta à antracnose, ao crestamento bacteriano comum e com características agronômicas favoráveis. Pesquisa Agropecuária Gaúcha, v.5, p.283-292, 1999 . 
COSTA, J.G.C.; RAVA, C.A.; SARTORATO, A.; PURÍSSIMO, J.D. Catálogo de linhagens de feijoeiro-comum (Phaseolus vulgaris L.) do CNPAF: reação às principais doenças e avaliação de características agronômicas. Goiânia: Embrapa-CNPAF, 1990. 21p. (Embrapa-CNPAF. Documentos, 32).

CRUZ, C.D.; CASTOLDI, F.L. Decomposição da interação genótipos $\mathrm{x}$ ambientes em partes simples e complexa. Revista Ceres, v.38, p.422-430, 1991.

DUARTE, J.B.; VENCOVSKY, R. Interação genótipos x ambientes: uma introdução à análise AMMI. Ribeirão Preto: Sociedade Brasileira de Genética, 1999. 60p. (Série monográfica, 9).

DUARTE, J.B.; ZIMMERMAN, M.J. de O. Adaptabilidade e estabilidade de rendimento de genótipos de feijão-comum. Pesquisa Agropecuária Brasileira, v.29, p.25-32, 1991.

EBERHART, S.A.; RUSSELL, W.A. Stability parameters for comparing varieties. Crop Science, v.6, p.36-40, 1966.

FARIA, L.C.; COSTA, J.G.C.; RAVA, C.A.; DEL PELOSO, M.J.; MELO, L.C.; CARNEIRO, G.E.S.; SOARES, D.M.; DIAZ, J.L.C.; ABREU, A.F.B.; FARIA, J.C.; SARTORATO, A.; SILVA, H.T.; BASSINELO, P.Z.; ZIMMERMANN, F.J.P. BRS Requinte: new common bean carioca cultivar with the delayed grain darkness. Crop Breeding and Applied Biotechnology, v.4, p.366-368, 2004.

FARIA, L.C.; DEL PELOSO, M.J.; MELO, L.C.; COSTA, J.G.C.; RAVA, C.A.; LEMES, G.C.; CABRERADIAZ, J.L.; ABREU, A.F.B.; ZIMMERMANN, F.J.P. Adaptabilidade e estabilidade da cultivar BRS Horizonte em diferentes regiões brasileiras. Santo Antônio de Goiás: Embrapa Arroz e Feijão, 2005. 4p. (Embrapa Arroz e Feijão. Comunicado técnico, 105).

GAUCH, H.G. Model selection and validation for yield trials with interaction. Biometrics, v.44, p.705-715, 1988.

GAUCH, H.G.; ZOBEL, R.W. AMMI analysis of yield trials. In: KANG, M.S.; GAUCH, H.G. (Ed.). Genotype by environment interaction. Boca Raton: CRC Press, 1996. v.4, p.85-122.
LIN, C.S.; BINNS, M.R. A superiority measure of cultivar performance for cultivar $\mathrm{x}$ location data. Canadian Journal of Plant Science, v.68, p.193-198, 1988.

LIN, C.S.; BINNS, M.R.; LEFKOVITCH, L.P. Stability analysis: where do we stand? Crop Science, v.26, p.894-900, 1986.

MELO, L.C.; FARIA, L.C.; DEL PELOSO, M.J.; COSTA, J.G.C.; RAVA, C.A.; LEMES, G.C.; CABRERADIAZ, J.L.; ABREU, A.F.B.; ZIMMERMANN, F.J.P. Adaptabilidade e estabilidade de produção da cultivar BRS Supremo em diferentes regiões brasileiras. Santo Antônio de Goiás: Embrapa Arroz e Feijão, 2005a. 4p. (Embrapa Arroz e Feijão. Comunicado técnico, 104).

MELO, L.C.; FARIA, L.C.; RAVA, C.A.; DEL PELOSO, M.J.; COSTA, J.G.C.; CABRERA DIAZ, J.L.; FARIA, J.C.; SILVA, H.T.; SARTORATO, A.; BASSINELO, P.Z.; ZIMMERMANN, F.J.P. BRS Horizonte: new bean variety of the carioca grain type. Crop Breeding and Applied Biotechnology, v.5, p.473-474, 2005b.

MELO, L.C.; SANTOS, J.B.; FERREIRA, D.F. Mapeamento de QTLs para reação ao oídio e mancha-angular do feijoeiro-comum em diferentes locais. Pesquisa Agropecuária Brasileira, v.37, p.11151126, 2002.

RAMALHO, M.A.P.; SANTOS, J.B.; ZIMMERMANN, M.J. Genética quantitativa em plantas autógamas: aplicações ao melhoramento do feijoeiro. Goiânia: Ed. da UFG, 1993. 271p.

SILVA, W.C.J.; DUARTE, J.B. Métodos estatísticos para estudo de adaptabilidade e estabilidade fenotípica em soja. Pesquisa Agropecuária Brasileira, v.41, p.23-30, 2006.

TEIXEIRA, F.F. Mapeamento de QTLs para caracteres do feijoeiro por meio de microssatélites. 2004. 189p. Tese (Doutorado) - Universidade Federal de Lavras, Lavras.

VENCOVSKY, R.; BARRIGA, P. Genética biométrica aplicada no fitomelhoramento. Ribeirão Preto: Sociedade Brasileira de Genética, 1992. 496p.

ZOBEL, R.W.; WRIGHT, M.J.; GAUCH, H.G. Statistical analysis of a yield trial. Agronomy Journal, v.80, p.388-393, 1988. 